\title{
Catalytic Effects of the New Schiff Base Metal Complexes on the Conversion of Benzyl Alcohol to Benzaldehyde and Benzoic Acid
}

\section{Cengiz Ayhan Ziba}

Kahramanmaraş Sutcu Imam University

Mustafa Dolaz ( $\sim$ dolazmustafa@gmail.com )

Kahramanmaraş Sutcu Imam University

Nuran Celikci

Kahramanmaraş Sutcu Imam University

\section{Research Article}

Keywords: Schiff Base, Metal complexes, Catalyst, Benzyl alcohol oxidation

Posted Date: July 16th, 2021

DOl: https://doi.org/10.21203/rs.3.rs-708362/v1

License: (c) (i) This work is licensed under a Creative Commons Attribution 4.0 International License.

Read Full License 


\section{Abstract}

In this study, two new salicylidene hydroxyl ligands $\left(\mathrm{HL}^{1}\right.$ and $\left.\mathrm{HL}^{2}\right)$ and their metal complexes $\left(\mathrm{Cu}^{2+}, \mathrm{Mn}^{2+}\right.$, $\mathrm{Fe}^{3+}, \mathrm{Ru}^{3+}, \mathrm{Cr}^{3+}$, and $\mathrm{VO}^{2+}$ ) were synthesized and characterized by the spectroscopic and analytical methods. The molecular structure of the ligand $\mathrm{HL}^{1}$ was determined by a single-crystal X-ray diffraction study. Catalytic effects of the Schiff base metal complexes on benzyl alcohol were investigated in the $\mathrm{H}_{2} \mathrm{O}_{2}$ medium. In this oxidation reaction, the percent conversion of benzyl alcohol to benzaldehyde and benzoic acid was determined as \%benzaldehyde and \%benzoic acid by the gas chromatography (GC) method. Finally, the synthesized metal complexes found the highest catalytic effect that $\mathrm{Co}$ and $\mathrm{Mn}$ metal complexes $97-98 \%$ benzyl alcohol conversion. And maximum \%benzoic acid formation is seen in $\mathrm{MnL}^{1}(39 \%)$ and $\mathrm{VOL}^{1}(58 \%)$ metal complexes.

\section{Introduction}

Schiff base is a nitrogen analog of an aldehyde or a ketone where the carbonyl group $(C=0)$ is replaced by the azomethine group $(\mathrm{C}=\mathrm{N})$. Schiff base ligands can form stable complexes with transition metal ions through nitrogen atom lone pair of azomethine group and additional donor atoms such as $\mathrm{O}, \mathrm{S}$, and $P$ present in their structure. [1-5]. Schiff base metal complexes exhibit significant catalytic activity in many biological systems and are used as efficient materials in the polymerization or oxidation reactions, pharmaceutical areas, functional dyes and pigments [6-14]. The imine group and additional functional groups such as hydroxyl groups in Schiff base, compounds are shown to be responsible for their biological activities $[15,16]$.

Transition metal complexes of Schiff base ligands have been applied as catalysts for both in homogeneous and heterogeneous catalytic reactions [17]. When the studies in the literature are examined, it is seen that most of the Schiff base metal complexes have high catalytic activity especially in high temperature and humid environments. Schiff base metal complexes are known to have a catalytic effect in the oxidation of sulfides, aldehydes, phenols, and styrenes. In addition, aromatic Schiff bases metal complexes have been used as catalysts in oxidation, hydrolysis, electro-reduction and degradation reactions. Also, some copper Schiff base complexes have been shown to increase the hydrolysis rate of amino acids $10-50$ times compared to pure copper ions $[17,18]$.

In our previous paper, we reported the synthesis and structural characterization and catalytic properties for alkane oxidation [19]. Due to the importance of azomethine compounds and in a continuance of our interest in the synthesis of Schiff base compounds having functional groups, the synthesis and spectral properties of two new azomethine compounds were reported herein. The proposed structure of the ligands and their complexes are shown in Scheme 1 and $2 .{ }^{1} \mathrm{H},{ }^{13} \mathrm{C} \mathrm{NMR}, \mathrm{IR}$, and Mass spectra data and elemental analysis results of the azo-azomethine compounds have been presented. Finally, the catalytic properties of the complexes for the oxidation of the benzyl alcohol were studied in the $\mathrm{H}_{2} \mathrm{O}_{2}$ medium. 


\section{Experimental \\ 2.1. General}

All starting materials (2,6-diisopropylaniline, 2,3-dihydroxybenzaldehyde, and 2,4-

dihydroxybenzaldehyde), metal salts ( $\mathrm{CoCl}_{2}, \mathrm{MnCl}_{2}, \mathrm{FeCl}_{3} \cdot 6 \mathrm{H}_{2} \mathrm{O}, \mathrm{RuCl}_{3} \cdot 2 \mathrm{H}_{2} \mathrm{O}, \mathrm{CrCl}_{3} \cdot 6 \mathrm{H}_{2} \mathrm{O}$, and $\mathrm{VOSO}_{4} \cdot \mathrm{H}_{2} \mathrm{O}$ ) and organic solvents were purchased analytical purity from Sigma-Aldrich and used as received.

Elemental analyses (CHN) were performed using a Lecochns 932 elemental analyzer. Infrared (IR) spectra of the ligands and their complexes were obtained using ATR $\left(4000-450 \mathrm{~cm}^{-1}\right)$ with a Perkin Elmer spectrum 400 Fourier transform (FT)-IR spectrophotometer. ${ }^{1} \mathrm{H}-\mathrm{NMR}$ spectra of the ligands were recorded on Bruker $-400 \mathrm{MHz}$ instrument. TMS was used as the internal standard and $\mathrm{CDCl}_{3}$ as the solvent.

Furthermore, XRD and SEM were used. The thermal analysis studies of the complexes were performed on a Perkin Elmer Pyris Diamond DTA/TG Thermal System under the nitrogen atmosphere at a heating rate of $20^{\circ} \mathrm{C} / \mathrm{min}$. Data collection for X-ray crystallography was completed using a Bruker APEX2 CCD diffractometer and data reduction was performed using Bruker SAINT [20]. SHELXS97 was used to solve and SHELXL2014/6 to refine the structure [21, 22].

\subsection{Synthesis of Schiff-base ligands $\left(H L^{1}-H L^{2}\right)$}

2,6-Diisopropilanilin $(1.779 \mathrm{~g}, 10 \mathrm{mmol})$ was dissolved in ethanol $(30 \mathrm{~mL})$ and the corresponding aldehyde (2,3-dihydroxybenzaldehyde and 2,4-dihydroxybenzaldehyde) $(0,138 \mathrm{~g}, 1 \mathrm{mmol})$ was added slowly. The yellow solution was refluxed for $6 \mathrm{~h}$ and the solvent was removed on a rotary evaporator. The yellow solid was washed with water $(2 \mathrm{~mL})$ and hexane $(4 \mathrm{~mL})$. The products were dried in air. Single crystal of the ligand $\mathrm{HL}^{1}$ was obtained recrystallization from the $\mathrm{CHCl}_{3}$ solution (Scheme 1).

$\mathrm{HL}^{1}$ - Yield: $92 \%$, m.p. $134^{\circ} \mathrm{C}$. Color: red-brown. Analysis Calc. for $\mathrm{C}_{19} \mathrm{H}_{23} \mathrm{NO}_{2}$ (MW: $297.38 \mathrm{~g} / \mathrm{mol}$ ): C, 76,73; H, 7,80; N, 4,71\%. Found: C, 76,66; H, 7,87; N, 4,77\%.IR (ATR, $\mathrm{cm}^{-1}$ ): 3461, 3062, 2962, 2922, 2865, $1629,1583,1455,1366,1325,1270,1203,1177,1101,1029,933,868,837,800,777,762,721,556$, 505. ${ }^{1} \mathrm{HNMR}$ : $\left(\mathrm{CDCl}_{3}\right.$ as solvent, $\delta$ in ppm): $1.22\left(12 \mathrm{H}, d,-\mathrm{CH}_{3}\right), 3.02\left(2 \mathrm{H}, m,-\mathrm{CH}_{2}-\right), 6.90-7.23(6 \mathrm{H}, d$, aromatic protons), $8.32(1 \mathrm{H}, \mathrm{s},-\mathrm{CH}=\mathrm{N}-)$.

$\mathrm{HL}^{2}$-Yield: $95 \%$, m.p. $140^{\circ} \mathrm{C}$. Color: orange. Analysis Calc. for $\left(\mathrm{C}_{19} \mathrm{H}_{23} \mathrm{NO}_{2}\right)(\mathrm{MW}: 297.38 \mathrm{~g} / \mathrm{mol}) \mathrm{C}, 76,73$; H, 7, 80; N, 4, 71 \%. Found: C, 76,18; H, 7,84; N, 4,68 \%.IR (ATR, cm ${ }^{-1}$ ): 3162, 2960, 2865, 1626, 1584, 1519, 1463, 1322, 1256, 1214, 1169, 1120, 1057, 972, 931, 876, 842, 794, 751, 691, 664, 545, 479.NMR: (CDCl as solvent, $\delta$ in ppm): $1.22\left(12 \mathrm{H}, d,-\mathrm{CH}_{3}\right), 3.05\left(2 \mathrm{H}, m,-\mathrm{CH}_{2}-\right), 6.48-7.22(6 \mathrm{H}, d$, aromatic protons), 8.15 $(1 \mathrm{H}, \mathrm{s},-\mathrm{CH}=\mathrm{N}-)$.

\subsection{Synthesis of the Metals complexes}

$\mathrm{Co}(\mathrm{II}), \mathrm{Mn}(\mathrm{II}), \mathrm{Fe}(\mathrm{III}), \mathrm{Ru}(\mathrm{III}), \mathrm{Cr}(\mathrm{III})$ and $\mathrm{VO}(\mathrm{II})$ complexes were synthesized according to the general procedure: metal salts $\left(\mathrm{CoCl}_{2}, \mathrm{MnCl}_{2}, \mathrm{FeCl}_{3} \cdot 6 \mathrm{H}_{2} \mathrm{O}, \mathrm{RuCl}_{3} \cdot 2 \mathrm{H}_{2} \mathrm{O}, \mathrm{CrCl}_{3} \cdot 6 \mathrm{H}_{2} \mathrm{O}\right.$, and $\left.\mathrm{VOSO}_{4} \cdot \mathrm{H}_{2} \mathrm{O}\right)(1 \mathrm{mmol})$ in 
methanol $(30 \mathrm{~mL})$ was added to Schiff base ligands $(0.595 \mathrm{~g}, 2 \mathrm{mmol})$ in methanol. The resulting solutions were refluxed for 6 hours. The precipitations were collected and washed with methanol (Scheme 2). After the products were dried in a vacuum medium. The mass spectra are given in the supplementary file (Fig. S1-12). The analytic values of these products are shown below.

[HL ${ }^{1}$-Co]; Yield: 84\% (based on Co(II)). Color: Brown. Elemental analysis data: Anal. (\%) Calculated for [Co( $\left(\mathrm{L}^{1}\right)_{2}$ ] $\mathrm{C}_{38} \mathrm{H}_{44} \mathrm{~N}_{2} \mathrm{O}_{4} \mathrm{Co}$ (MW: $669.73 \mathrm{~g} / \mathrm{mol}$ ): C, 68.15; H, 6.79; N, 4.09 Found (\%): C, 68.33; H, 6.80; N, 4.20. IR (ATR, v, cm ${ }^{-1}$ ): 3458, 2961, 1620, 1583, 1456, 1365, 1324, 1269, 1202, 1176, 1100, 1058, 1028, $933,867,836,800,777,761,723,504 \mathrm{~cm}^{-1}$. Mass spec. (ESI) (m/z (rel. intensity), assignment): 635.16 $(100 \%)\left\{\left[\mathrm{Co}\left(\mathrm{L}^{1}\right)_{2}-\mathrm{OH}\right] \mathrm{H}\right\}^{+}, 651.16(31.48 \%)\left\{\left[\mathrm{Co}\left(\mathrm{L}^{1}\right)_{2}\right] \mathrm{H}\right\}^{+}$.

[HL ${ }^{1}-\mathrm{Mn}$ ]; Yield: $81 \%$ (based on $\mathrm{Mn}(\mathrm{II})$ ). Color: Orange. Elemental analysis data: Anal. (\%) Calculated for [Mn ( $\left.\left(\mathrm{L}^{1}\right)_{2}\right] \mathrm{C}_{38} \mathrm{H}_{44} \mathrm{~N}_{2} \mathrm{O}_{4} \mathrm{Mn}$ (MW: $647.27 \mathrm{~g} / \mathrm{mol}$ ): C, 70.47; $\mathrm{H}, 6.85 ; \mathrm{N}, 4.33$ Found (\%): C, 70.61; $\mathrm{H}, 6.80 ; \mathrm{N}$, 4.31. IR (ATR, v, cm $\left.{ }^{-1}\right)$ : 3458, 2962, 1621, 1584, 1455, 1365, 1324, 1269, 1201, 1177, 1100, 1058, 1028, $933,868,837,800,777,761,724,506 \mathrm{~cm}^{-1}$. Mass spect. (ESI) (m/z (rel. intensity), assignment): 648.13 $(100 \%)\left\{\left[\mathrm{Mn}\left(\mathrm{L}^{1}\right)_{2}\right] \mathrm{H}\right\}^{+}, 630.29(10.27 \%)\left\{\left[\mathrm{Mn}\left(\mathrm{L}^{1}\right)_{2}-\mathrm{OH}\right] \mathrm{H}\right\}^{+}$.

[HL ${ }^{1}$-Fe]; Yield: 83\% (based on Fe(III)). Color: Black. Elemental analysis data: Anal. (\%) Calculated for $\left[\mathrm{Fe}\left(\mathrm{L}^{1}\right)_{2} \mathrm{ClH}_{2} \mathrm{O}\right] \mathrm{C}_{38} \mathrm{H}_{44} \mathrm{~N}_{2} \mathrm{O}_{4} \mathrm{FeCl} . \mathrm{H}_{2} \mathrm{O}$ (MW: $719.52 \mathrm{~g} / \mathrm{mol}$ ): C, 63.43; $\mathrm{H}, 6.16 ; \mathrm{N}, 3.89$ Found (\%): C, 62.78; $\mathrm{H}$, 6.03; N, 3.68. IR (ATR, v, cm $\left.{ }^{-1}\right)$ : 2962, 1621, 1462, 1364, 1241, 1219, 1161, 1096, 1042, 983, 867, 799, 783, $764,734,615,505 \mathrm{~cm}^{-1}$. Mass spect. (ESI) (m/z (rel. intensity), assignment): $648.13(100 \%)\left\{\left[\mathrm{Fe}\left(\mathrm{L}^{1}\right)_{2}\right] \mathrm{H}\right\}^{+}$, $684.11(13.54 \%)\left\{\left[\mathrm{Fe}\left(\mathrm{L}^{1}\right)_{2} \mathrm{Cl}\right] \mathrm{H}\right\}^{+}$.

[HL ${ }^{1}$-Cr]; Yield: 84\% (based on $\mathrm{Cr}(\mathrm{III})$ ). Color: Brown. Elemental analysis data: Anal. (\%) Calculated for [Cr( $\left(\mathrm{L}^{1}\right)_{2} \mathrm{ClH}_{2} \mathrm{O}$ ] $\mathrm{C}_{38} \mathrm{H}_{44} \mathrm{~N}_{2} \mathrm{O}_{4} \mathrm{CrCl} . \mathrm{H}_{2} \mathrm{O}$ (MW: $697.25 \mathrm{~g} / \mathrm{mol}$ ): C, 65.37; $\mathrm{H}, 6.64 ; \mathrm{N}, 4.01$ Found (\%): C, 64.90; $\mathrm{H}$, 6.34; N, 3.95. IR (ATR, v, cm $\left.{ }^{-1}\right)$ : 2961, 1621, 1548, 1385, 1364, 1244, 1219, 1162, 1043, 867, 798, 764, 733, $644,593,504 \mathrm{~cm}^{-1}$. Mass spect. (ESI) (m/z (rel. intensity), assignment): $644.09(37.64 \%)\left\{\left[\mathrm{Cr}\left(\mathrm{L}^{1}\right)_{2}\right] \mathrm{H}\right\}^{+}$, $680.13(81.21 \%)\left\{\left[\mathrm{Cr}\left(\mathrm{L}^{1}\right)_{2} \mathrm{Cl}\right] \mathrm{H}\right\}^{+}$.

[HL ${ }^{1}$-Ru]; Yield: 96\% (based on Ru(III)). Color: Black. Elemental analysis data: Anal. (\%) Calculated for $\left[\mathrm{Ru}\left(\mathrm{L}^{1}\right)_{2} \mathrm{ClH}_{2} \mathrm{O}\right] \mathrm{C}_{38} \mathrm{H}_{44} \mathrm{~N}_{2} \mathrm{O}_{4} \mathrm{RuCl} . \mathrm{H}_{2} \mathrm{O}$ (MW: $837.27 \mathrm{~g} / \mathrm{mol}$ ): C, 54.50; $\mathrm{H}, 6.74 ; \mathrm{N}, 3.35$ Found (\%): C, 54.48; H, 6.47; N, 3.26. IR (ATR, v, cm ${ }^{-1}$ ): 2962, 1621, 1581, 1462, 1386, 1219, 1162, 1043, 866, 764, 733, 617, $506 \mathrm{~cm}^{-1}$. Mass spect. (ESI) (m/z (rel. intensity), assignment): $729.05(48.80 \%)\left\{\left[\mathrm{Ru}\left(\mathrm{L}^{1}\right)_{2} \mathrm{Cl}\right] \mathrm{H}\right\}^{+}, 692.18$ (9.66\%) $\left\{\left[\mathrm{Ru}\left(\mathrm{L}^{1}\right)_{2}\right] \mathrm{H}\right\}^{+}$.

[HL ${ }^{1}$-VO]; Yield: 94\% (based on VO(II)). Color: Black. Elemental analysis data: Anal. (\%) Calculated for [VO $\left.\left(\mathrm{L}^{1}\right)_{2}\right] \mathrm{C}_{38} \mathrm{H}_{44} \mathrm{~N}_{2} \mathrm{O}_{4} \mathrm{VO}$ (MW: $767.33 \mathrm{~g} / \mathrm{mol}$ ): C, 59.44; $\mathrm{H}, 7.35 ; \mathrm{N}, 3.65$ Found (\%): C, 59.22; H, 7.25; N, 
3.57. IR (ATR, v, $\mathrm{cm}^{-1}$ ): 2961, 1622, 1568, 1456, 1386, 1364, 1219, 1171, 1044, 849, 736, 618, $497 \mathrm{~cm}^{-1}$. Mass spect. (ESI) (m/z (rel. intensity), assignment): $616.05(38.60 \%)\left\{\left[\mathrm{VO}\left(\mathrm{L}^{1}\right)_{2}\right] \mathrm{H}\right\}^{+}$.

[HL ${ }^{2}$-Co]; Yield: $96 \%$ (based on Co(II)). Color: Light Green. Elemental analysis data: Anal.(\%) Calculated for [Co $\left.\left(\mathrm{L}^{2}\right)_{2}\right] \mathrm{C}_{38} \mathrm{H}_{44} \mathrm{~N}_{2} \mathrm{O}_{4} \mathrm{Co}(\mathrm{MW}: 687.28 \mathrm{~g} / \mathrm{mol}$ ): C, 66.32; $\mathrm{H}, 7.04 ; \mathrm{N}, 4.07$ Found (\%): C, 66.32; $\mathrm{H}, 7.08 ; \mathrm{N}$, 4.10. IR (ATR, v, $\mathrm{cm}^{-1}$ ): 3478, 2961, 1619, 1594, 1518, 1455, 1362, 1324, 1255, 1214, 1169, 1121, 1058, $977,931,876,851,795,752,645,477 \mathrm{~cm}^{-1}$. Mass spect. (ESI) (m/z (rel. intensity), assignment): 652.12 $(100 \%)\left\{\left[\mathrm{Co}\left(\mathrm{L}^{2}\right)_{2}\right] \mathrm{H}\right\}^{+}, 635.19(12.32 \%)\left\{\left[\mathrm{Co}\left(\mathrm{L}^{2}\right)_{2}-\mathrm{OH}\right] \mathrm{H}\right\}^{+}$.

[HL ${ }^{2}-\mathrm{Mn}$ ]; Yield: 97\% (based on Mn(II)). Color: Beige. Elemental analysis data: Anal. (\%) Calculated for $\left[\mathrm{Mn}\left(\mathrm{L}^{2}\right)_{2}\right] \mathrm{C}_{38} \mathrm{H}_{44} \mathrm{~N}_{2} \mathrm{O}_{4} \mathrm{Mn}(\mathrm{MW}: 647.27 \mathrm{~g} / \mathrm{mol}): \mathrm{C}, 63.41 ; \mathrm{H}, 7.28 ; \mathrm{N}, 3.89$ Found (\%): C, 63.38; $\mathrm{H}, 7.20 ; \mathrm{N}$, 3.81. IR (ATR, v, cm ${ }^{-1}$ ): 3197, 2961, 1618, 1584, 1495, 1323, 1255, 1214, 1169, 1121, 1058, 977, 876, 839, $794,752,645,478,461 \mathrm{~cm}^{-1}$. Mass spect. (ESI) (m/z (rel. intensity), assignment): $646.29(11.32 \%)$ $\left\{\left[\mathrm{Mn}\left(\mathrm{L}^{1}\right)_{2}\right] \mathrm{H}\right\}^{+}, 632.19(10.68 \%)\left\{\left[\mathrm{Mn}\left(\mathrm{L}^{1}\right)_{2}-\mathrm{OH}\right] \mathrm{H}\right\}^{+}$.

[HL ${ }^{2}$-Fe]; Yield: 72\% (based on Fe(III)). Color: Black. Elemental analysis data: Anal. (\%) Calculated for $\left[\mathrm{Fe}\left(\mathrm{L}^{2}\right)_{2} \mathrm{ClH}_{2} \mathrm{O}\right] \mathrm{C}_{38} \mathrm{H}_{44} \mathrm{~N}_{2} \mathrm{O}_{4} \mathrm{FeCl} . \mathrm{H}_{2} \mathrm{O}$ (MW: $774.15 \mathrm{~g} / \mathrm{mol}$ ): C, 58.96; $\mathrm{H}, 7.03 ; \mathrm{N}, 3.62$ Found (\%): $\mathrm{C}, 58.85 ; \mathrm{H}$, 7.11; N, 3.69. IR (ATR, v, cm ${ }^{-1}$ ): 2962, 1603, 1537, 1463, 1317, 1225, 1169, 1123, 977, 851, 795, 751, 544, $484 \mathrm{~cm}-1$. Mass spect. (ESI) (m/z (rel. intensity), assignment): $684.02(11,15 \%)\left\{\left[\mathrm{Fe}\left(\mathrm{L}^{2}\right)_{2} \mathrm{Cl}\right] \mathrm{H}\right\}^{+}, 649.10$ (17.94\%) $\left\{\left[\mathrm{Fe}\left(\mathrm{L}^{2}\right)_{2}\right] \mathrm{H}\right\}^{+}$

[HL ${ }^{2}$-Cr]; Yield: 84\% (based on $\mathrm{Cr}(\mathrm{III})$ ). Color: Olive. Elemental analysis data: Anal. (\%) Calculated for [ $\left.\mathrm{Cr}\left(\mathrm{L}^{2}\right)_{2} \mathrm{ClH}_{2} \mathrm{O}\right] \mathrm{C}_{38} \mathrm{H}_{44} \mathrm{~N}_{2} \mathrm{O}_{4} \mathrm{CrCl} . \mathrm{H}_{2} \mathrm{O}$ (MW: $715.26 \mathrm{~g} / \mathrm{mol}$ ): C, 63.72; $\mathrm{H}, 6.76 ; \mathrm{N}, 3.91$ Found (\%): C, 63.74; $\mathrm{H}$, 6.72; N, 3.96. IR (ATR, v, cm $\left.{ }^{-1}\right)$ : 2962, 1580, 1531, 1482, 1385, 1347, 1227, 1173, 1122, 978, 851, 795, 752, $639,544,484,465 \mathrm{~cm}^{-1}$. Mass spect. (ESI) (m/z (rel. intensity), assignment): 644.33 (9.13\%) $\left\{\left[\mathrm{Cr}\left(\mathrm{L}^{1}\right)_{2}\right] \mathrm{H}\right\}^{+}, 680.03(16.28 \%)\left\{\left[\mathrm{Cr}\left(\mathrm{L}^{1}\right)_{2} \mathrm{Cl}\right] \mathrm{H}\right\}^{+}$.

[HL ${ }^{2}$-Ru]; Yield: 63\% (based on Ru(III)). Color: Brown. Elemental analysis data: Anal. (\%) Calculated for $\left[\mathrm{Ru}\left(\mathrm{L}^{2}\right)_{2} \mathrm{ClH}_{2} \mathrm{O}\right] \mathrm{C}_{38} \mathrm{H}_{44} \mathrm{~N}_{2} \mathrm{O}_{4} \mathrm{RuCl} . \mathrm{H}_{2} \mathrm{O}$ (MW: 765.33g/mol): C, 59.64; $\mathrm{H}, 6.32 ; \mathrm{N}, 3.66$ Found (\%): C, 59.73; $\mathrm{H}$, 6.30; N, 3.61. IR (ATR, v, cm ${ }^{-1}$ ): 2962, 1608, 1581, 1463, 1317, 1224, 1171, 1123, 975, 850, 795, 751, 631, $485 \mathrm{~cm}^{-1}$. Mass spect. (ESI) (m/z (rel. intensity), assignment): $727.04(13.01 \%)\left\{\left[\mathrm{Ru}\left(\mathrm{L}^{1}\right)_{2} \mathrm{Cl}\right] \mathrm{H}\right\}^{+}, 697.14$ (9.83\%) $\left\{\left[\mathrm{Ru}\left(\mathrm{L}^{1}\right)_{2}\right] \mathrm{H}\right\}^{+}$.

[HL ${ }^{2}$-VO]; Yield: 82\% (based on VO(II)). Colour: Black. Elemental analysis data: Anal. (\%) Calculated for $\left[\mathrm{VO}\left(\mathrm{L}^{2}\right)_{2}\right] \mathrm{C}_{38} \mathrm{H}_{44} \mathrm{~N}_{2} \mathrm{O}_{4} \mathrm{VO}$ (MW: $\left.731.78 \mathrm{~g} / \mathrm{mol}\right): \mathrm{C}, 62.37 ; \mathrm{H}, 7.16 ; \mathrm{N}, 3.83$ Found (\%): C, 62.52; $\mathrm{H}, 7.14 ; \mathrm{N}$, 3.81. IR (ATR, v, cm ${ }^{-1}$ ): 2962, 1620, 1568, 1463, 1320, 1227, 1169, 1021, 974, 852, 794, 750, 603, $545 \mathrm{~cm}^{-}$ 1. Mass spect. (ESI) (m/z (rel. intensity), assignment): $615.12(16.70 \%)\left\{\left[\mathrm{VO}\left(\mathrm{L}^{1}\right)_{2}\right] \mathrm{H}\right\}^{+}$. 


\subsection{X-ray Structure solution and refinement for the compound}

X-ray crystallographic data for $\mathrm{HL}^{1}$ were collected at 293(2) $\mathrm{K}$ on a Bruker Apexll CCD diffractometer using Mo-Ka radiation $(\lambda=0.71073 \AA$ ). Data reduction was performed using Bruker SAINT [20]. The structure was solved by direct methods and refined on $F^{2}$ using all the reflections. All the non-hydrogen atoms were refined using anisotropic atomic displacement parameters and hydrogen atoms bonded to carbon and oxygen atoms were located at the calculated positions using a riding model and refined with temperature factors riding on the carrying atoms. Hydrogen atoms bonded to oxygen atoms were located from difference maps and allowed to refine with temperature factors riding on those of the carrier atoms. The crystal data and details of the structure solutions and refinement are given in Table 1. 
Table 1

\begin{tabular}{|c|c|}
\hline \multicolumn{2}{|c|}{ Crystallographic data for $\mathrm{HL}^{1}$} \\
\hline Identification code & $H^{1}$ \\
\hline Empirical formula & $\mathrm{C}_{19} \mathrm{H}_{23} \mathrm{NO}_{2}$ \\
\hline Formula weight & 297.38 \\
\hline Crystal system & Triclinic \\
\hline Space group & $P-1$ \\
\hline Unit cell a $(\AA)$ & $8.5894(5)$ \\
\hline$b(\AA)$ & $9.8725(6)$ \\
\hline$c(\AA)$ & $11.6217(7)$ \\
\hline$a\left(^{\circ}\right)$ & $91.337(2)$ \\
\hline$\beta\left({ }^{\circ}\right)$ & 106.887(2) \\
\hline$Y\left({ }^{\circ}\right)$ & $113.159(2)$ \\
\hline Volume (Å3) & $856.35(9)$ \\
\hline Z & 2 \\
\hline Abs. coeff. $\left(\mathrm{mm}^{-1}\right)$ & 0.074 \\
\hline Refl. collected & 46896 \\
\hline Ind. Refl. $\left[\mathrm{R}_{\text {int }}\right]$ & $4285[0.0372]$ \\
\hline 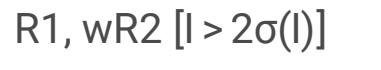 & $0.0678,0.1869$ \\
\hline R1, wR2 (all data) & $0.0891,0.2084$ \\
\hline CCDC & 1990293 \\
\hline
\end{tabular}

\subsection{Benzyl alcohol oxidation}

Conversion amounts of benzyl alcohol to benzaldehyde and benzoic acid were determined as a percentage using gas chromatography (using ZB-1 column (30 m length, $0.5 \mathrm{~nm}$ ID and $3.0 \mu \mathrm{m}$ film thickness) and flame ionization detector (FID)). The catalytic oxidation of benzyl alcohol was performed as follows: catalyst $(0.01 \mathrm{mmol})$, benzyl alcohol $(1 \mathrm{mmol})$ and $\mathrm{H}_{2} \mathrm{O}_{2}(2 \mathrm{mmol})$ were refluxed at $80^{\circ} \mathrm{C}$ for 8 hours. The catalyst: substrate: oxidant ratio is 1:100:200, respectively. The complexes were dissolved in 5 $\mathrm{mL}$ acetonitrile and then benzyl alcohol and $\mathrm{H}_{2} \mathrm{O}_{2}$ were added to the Erlenmeyer flask for each oxidation experiment (Fig. 1). After oxidation, $20 \mu \mathrm{l}$ of the sample was taken and was completed $2 \mathrm{~mL}$ with acetonitrile and injected by GC and GC-MS to analyze and characterize. The percentage of conversion of 
benzaldehyde and benzoic acid was calculated from a calibration curve that was prepared before analyses [22-25].

\section{Result And Discussion}

In this study, two new hydroxyls Schiff base ligands and their metal complexes were synthesized and characterized using spectroscopic and analytical methods. The ligands were prepared by reaction of one equivalent of diisopropylaniline and corresponding aldehyde in refluxing ethanol. Both ligands $\left(\mathrm{HL}^{1}\right.$ and $\mathrm{HL}^{2}$ ) are soluble mostly in organic solvents such as ethanol, methanol and chloroform and but insoluble in water.

The formation of the compounds was confirmed by ${ }^{1} \mathrm{H}-\mathrm{NMR}$ spectra Fig. $3-4 .{ }^{1} \mathrm{H}-\mathrm{NMR}$ spectra of the compounds were recorded in $\mathrm{CDCl}_{3}$. In the spectra of the $\mathrm{HL}^{1}$ and $\mathrm{HL}^{2}$, the doublet signals in the 1.22 ppm range can be attributed to the $\mathrm{CH}_{3}$ hydrogen atoms. The multiply in the 3.02-3.05 ppm range may be assigned to the $-\mathrm{CH}_{2}-$ group protons. The $-\mathrm{CH}_{2}-$ proton signals were observed in the range of 6.48$7.23 \mathrm{ppm}$ for both ligands. The azomethine $(-\mathrm{CH}=\mathrm{N}-)$ protons of the ligands were seen as singlet signals in the range of 8.15-8.32 ppm [26]. The ortho-hydroxy Schiff bases can exist in two tautomeric forms (phenol-imine and keto-amine tautomeric forms) and tautomeric transformations are followed by NMR and UV-Vis spectroscopies. The singlet signal due to the azomethine proton suggests the phenol-imine tautomeric form in solution.

Single crystals of the metal complexes were not isolated from organic solvents, and so solid structures of the metal complexes were not determined using single-crystal X-ray analysis. However, structures of the complexes were proposed by the analytical and spectroscopic data as shown in Schemes. Elemental analysis data of the ligands and their metal complexes are coherent with the theoretical values. The elemental analysis data were shown that the metal: ligand ratio is 1:2 in the metal complexes. Analysis data were supported by the proposed structure of the complexes.

Infrared spectra of the free ligands $\left(\mathrm{HL}^{1}\right.$ and $\left.\mathrm{HL}^{2}\right)$ and their complexes were studied. Then, the infrared spectra of the free ligands were compared with their metal complexes to access the coordination of the ligands to metal ions. In FT-IR spectra of the Schiff base ligands $\left(\mathrm{HL}^{1}\right.$ and $\left.\mathrm{HL}^{2}\right)$, the absence of $\mathrm{v}(\mathrm{C}=0)$ aldehyde group vibrations and formation of a new band at $1629 \mathrm{~cm}^{-1}$ has confirmed the formation of Schiff base ligands. FT-IR spectrum of $\mathrm{HL}^{1}$ is shown in Fig. 5 and the rest of the FT-IR spectra are given in the supplementary file (Fig. S13-15). In the infrared spectral data, the bands that were observed in the $2960-2845 \mathrm{~cm}^{-1}$ range can be attributed to the aliphatic $\mathrm{v}(\mathrm{C}-\mathrm{H})$ vibrations. The azomethine $\mathrm{v}(\mathrm{CH}=\mathrm{N})$ band stretching was observed in the $1629-1626 \mathrm{~cm}^{-1}$ range for both ligands. The shift of $-\mathrm{CH}=\mathrm{N}$ stretching frequencies in the free Schiff base ligands to lower values wave number values in metals complexes indicated the coordination of azomethine nitrogen to the metal ions. This suggests that azomethine nitrogen is coordinated to the metals ions. In the IR spectra of metal complexes imine bond stretches were observed at 1603 and $1620 \mathrm{~cm}^{-1}$, respectively. In the spectra of the ligands, the 
broadband due to the phenolic group $\mathrm{v}(\mathrm{O}-\mathrm{H})$ was observed $3100-3500 \mathrm{~cm}^{-1}$ range and this broadband disappeared in the spectra of the complexes confirming deprotonation and the coordination of the phenolic oxygen atom [27-31].

\subsection{Molecular Structure of ligand $\mathrm{HL}^{1}$}

Molecular structures of all three compounds are given in Fig. 6. The molecular structure is broadly similar, differing principally in the substitute group on the phenyl ring and the dihedral angle between the two aromatic rings. All the bond lengths and angles in the compound are within the normal ranges. All bond lengths and angles in the phenyl rings are within the normal $\mathrm{C} s p^{2}-\mathrm{C} s p^{2}$ values. The $\mathrm{X}$-ray data revealed that the compound favors the phenol-imine tautomeric form in the solid state. The azomethine linkage distance is within the range of normal $\mathrm{C}=\mathrm{N}$ values. Selected bond lengths and angles for the compound are given in Table 2.

Table 2

Hydrogen-bond geometry for the ligand $\left(\AA^{\circ},{ }^{\circ}\right)$.

\begin{tabular}{|c|c|c|c|c|}
\hline$D-\mathrm{H} \cdots A$ & $D-\mathrm{H}$ & $\mathrm{H} \cdots A$ & $D \cdots A$ & $D-\mathrm{H} \cdots A$ \\
\hline $\mathrm{O} 1-\mathrm{H} 1 \cdots \mathrm{N} 1$ & $0.86(3)$ & $1.82(3)$ & $2.623(2)$ & $154(3)$ \\
\hline $\mathrm{O} 2-\mathrm{H} 2 \cdots 03^{\mathrm{i}}$ & $0.82(3)$ & $1.97(3)$ & $2.725(2)$ & $154(3)$ \\
\hline
\end{tabular}

There is an intramolecular phenol-imine hydrogen bond $(01-\mathrm{H} \bullet . \bullet \mathrm{N} 1$ generating an $\mathrm{S}(6)$ hydrogen bond motif. Compound $\mathrm{HL}^{1}$ contains a second hydroxyl group and this involves an intramolecular hydrogen

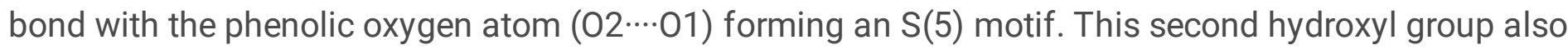
makes an intermolecular hydrogen bond with the phenolic oxygen atom of a neighboring molecule resulting in a hydrogen-bonded dimer with $\mathrm{D}_{2}{ }^{2}(4)$ hydrogen bond motif (under symmetry operation of $-x+$ $1,-y+1,-z+1)$ as shown in Fig. 7. Hydrogen bond parameters are listed in Table 3. 
Table 3

Bond lengths and angles for the ligand $\left(\AA,^{\circ}\right)$.

\begin{tabular}{|llll|}
\hline $\mathrm{P} 1-\mathrm{O} 3$ & $\mathbf{1 . 4 6 9 5 ( 1 4 )}$ & $\mathrm{C} 6-\mathrm{C} 1$ & $\mathbf{1 . 4 0 6 ( 3 )}$ \\
\hline $\mathrm{P} 1-05$ & $1.5677(17)$ & $\mathrm{C} 4-\mathrm{C} 3$ & $1.398(3)$ \\
\hline $\mathrm{P} 1-\mathrm{O} 4$ & $1.5744(14)$ & $\mathrm{C} 6-\mathrm{C} 5$ & $1.407(3)$ \\
\hline $\mathrm{P} 1-\mathrm{C} 14$ & $1.789(2)$ & $\mathrm{C} 6-\mathrm{C} 7$ & $1.452(2)$ \\
\hline $\mathrm{O} 4-\mathrm{C} 15$ & $1.450(2)$ & $\mathrm{C} 8-\mathrm{C} 9$ & $1.394(3)$ \\
\hline $\mathrm{O} 1-\mathrm{C} 1$ & $1.353(2)$ & $\mathrm{C} 8-\mathrm{C} 13$ & $1.398(3)$ \\
\hline $\mathrm{O} 2-\mathrm{C} 2$ & $1.361(2)$ & $\mathrm{C} 9-\mathrm{C} 10$ & $1.388(3)$ \\
\hline $\mathrm{O} 5-\mathrm{C} 17$ & $1.401(3)$ & $\mathrm{C} 11-\mathrm{C} 10$ & $1.388(3)$ \\
\hline $\mathrm{N} 1-\mathrm{C} 7$ & $1.287(2)$ & $\mathrm{C} 11-\mathrm{C} 12$ & $1.391(3)$ \\
\hline $\mathrm{N} 1-\mathrm{C} 8$ & $1.422(2)$ & $\mathrm{C} 11-\mathrm{C} 14$ & $1.511(3)$ \\
\hline $\mathrm{C} 2-\mathrm{C} 1$ & $1.403(2)$ & $\mathrm{C} 13-\mathrm{C} 12$ & $1.387(3)$ \\
\hline $\mathrm{C} 2-\mathrm{C} 3$ & $1.386(3)$ & $\mathrm{C} 15-\mathrm{C} 16$ & $1.491(3)$ \\
\hline $\mathrm{C} 5-\mathrm{C} 4$ & $1.379(3)$ & $\mathrm{C} 17-\mathrm{C} 18$ & $1.501(4)$ \\
\hline
\end{tabular}

The aromatic rings are considerably twisted from planarity due to the steric hindrance of isopropyl groups. The dihedral angles between the two aromatic rings (C1/C6-C14/C19) are 66.24(7). There is evidence of $\pi-\pi$ phenyl stacking interactions in $\mathrm{HL}^{1}$. The $\mathrm{C} 14-\mathrm{C} 19-\mathrm{C} 18$ section of the compound is stacked with the same section of an adjacent molecule under symmetry operation of $1-x,-y, 1-z$ with interplanar separation of $4.02 \AA$; C14 and C18 are separated by with $3.68 \mathrm{~A}^{\circ}$ (Fig. 8). Packing plot $\mathrm{HL}^{1}$ of the compounds were determined by $\pi-\pi$ stacking and $\mathrm{CH} \cdots \mathrm{O}$ weak hydrogen bond type interactions and packing diagram of $\mathrm{HL}^{1}$ viewing down the a axis is shown Fig. 9.

\subsection{Catalyst Effect in Benzyl Alcohol Oxidation}

The catalyst effect of metal complexes was firstly investigated on the oxidation of benzyl alcohol. The oxidation reaction of benzyl alcohol was initiated, 30min, 1, 2, 4, and 8 hours later, benzaldehyde and benzoic acid formation were determined by Gas Chromatography (GC) [22-25]. In the oxidation of benzyl alcohol, it has been understood that the transformations in the catalysis of metal complexes are higher than the catalyst-free oxidation. Among them, over $90 \%$ total conversion is observed in the catalysis of Co, $\mathrm{Mn}$ and Ru metal complexes, In the catalyst of $\mathrm{VOL}^{1}$, more than $90 \%$ and the most benzoic acid conversion is observed. In the catalyst of $\mathrm{MnL}^{1}$, the most amount of benzoic acid formation is observed. The least transformations were observed in Fe metal complexes ( $70 \%$ and $81 \%$ ) within their own groups (Fig. 10,11). In the literature, it can be seen that the similar structure Schiff base metal complexes have catalytic oxidation efficiency of $40-90 \%$ of benzyl alcohol [32-33]. 


\section{Conclusions}

In summary, two new Schiff base ligands and their $\mathrm{Cu}^{2+}, \mathrm{Mn}^{2+}, \mathrm{Fe}^{3+}, \mathrm{Ru}^{3+}, \mathrm{Cr}^{3+}$, and $\mathrm{VO}^{2+}$ complexes were synthesized and characterized. Elemental analyses confirm the chemical composition of the synthesized compounds while FT-IR, ${ }^{1} \mathrm{H}-\mathrm{NMR}$ spectroscopy confirms the functional groups and $-\mathrm{HC}=\mathrm{N}-$ imine groups. The metal-to-ligand ratios of the complexes were found to be 1:2. The crystal structure of free Schiff base ligand $\mathrm{HL}^{1}$ was successfully determined by single-crystal X-ray diffraction study. The complexes prepared were used as a catalyst in benzyl alcohol. The $\mathrm{VOL}^{1}, \mathrm{MnL}^{1}$, and $\mathrm{CrL}^{2} \mathrm{ClH}_{2} \mathrm{O}$ complexes were found to provide more efficient conversion to oxidized products under given conditions.

Finally, of the synthesized metal complexes, it was found the highest catalytic effect that Co and Mn metal complexes $97-98 \%$ benzyl alcohol conversion. And maximum \%benzoic acid formation is seen in $\mathrm{MnL}^{1}(39 \%)$ and $\mathrm{VOL}^{1}(58 \%)$ metal complexes.

\section{Declarations}

\section{Acknowledgements}

This work was supported by Kahramanmaras Sutcu Imam University (BAP project no: 2013/2-27 D). Authors thank to Prof. Dr. Serhan Uruş and Dr. Muhammet Köse for helping in catalysis and X-ray crystallographic studies.

\section{References}

1. H. Schiff, Ann. Suppl. 1864, 3, 343

2. G. Wilkinson, R.D. Gillard, J. A. Mc Cleverty, Properties and Applications of Coordination Compounds (Pergamon Press, Oxford, 1987)

3. M. Dolaz, M. Tümer, Trans. Metal Chem. 29, 5516 (2004)

4. A. Filarowski, A. Koll, T. Glowiok, J. Chem. Soc. Perkin Trans. 2, 835 (2002)

5. P.A. Vigato, S. Tamburini, Coor. Chem. Rev. 248, 1717 (2004)

6. A.M. Abu-Dief, I.M.A. Mohamed, Basic J. and Appl. Scien. 4, 119 (2015)

7. A.Y. Robin, K.M. Fromm, Coor. Chem. Rev. 250, 2127 (2006)

8. M. Ahmed, Abu-Dief, Raúl Díaz-Torres, Eva Carolina Sañudo, Laila H Abdel-Rahman, Núria AliagaAlcalde, Polyhedron 64. 2013, 203-208

9. L.H. Abdel-Rahman, A.M. Abu-Dief, M.S.S. Adam, S.K. Hamdan, Catal. Lett. 146, 1373 (2016)

10. L.H. Abdel Rahman, A.M. Abu-Dief, M. Basha, A. A. H. Abdel Mawgoud. Appl Organometal Chem. 31(11), e3750 (2017)

11. S.I. Al-Saeedi, L.H. Abdel-Rahman, A.M. Abu-Dief, S.M. Abdel-Fatah, T.M. Alotaibi, A.M. Alsalme, A. Nafady, Catalysts. 8, 452 (2018) 
12. L.H. Abdel Rahman, A.M. Abu Dief, M.R. Shehata, M. Faten, A.A. Atlam, Hassan Abdel Mawgoud. Appl Organometal Chem 33(4), e4699 (2019)

13. M. Ahmed. H. Abu Dief Laila, Abdel Rahman Azza A. Hassan Abdel Mawgoud. Appl Organometal Chem. 34(2), e5373 (2020)

14. W.M. Singh, B.C. Dash, Pesticide. 22, 33 (1988)

15. G. Ceyhan, M. Kose, M. Tumer, I. Demirtas, Spect. Chim Acta Part A. 149, 731 (2015)

16. P.I. Nagy, W.M.F. Fabian, J. Phys. Chem. B. 110, 25026 (2006)

17. W. Zhang, J.L. Loebach, S.R. Wilson, E.N. Jacobsen, J. Am. Chem. Soc. 112, 2801 (1990)

18. M. Dolaz, M. Kose, Appl Organometal Chem 33, e4970 (2019)

19. Bruker, APEX2 and SAINT Bruker AXS Inc. 1998

20. G.M. Sheldrick, Acta Cryst. A 64, 112 (2008)

21. A. Mobinikhaledi, M. Zendehdel, P. Safari, Transition Met Chem. 39, 431-442 (2014)

22. G.C. Behera, K.M. Parida, Appl Catal A: General. 414, 413 (2012), - , 245-253.

23. W.A. Herrmann, J.P. Zoller, R.W. Fischer, J Organometc Chem 579, 404-407 (1999)

24. A. Dasgupta, P.E. Humphrey, J. Chromatogr. B 708, 299-303 (1998)

25. C.A. Tellez, S.V. de Souza, W.O. Lin, Spectrochim. Acta A 56, 653 (2000)

26. L.H. Abdel-Rahman, R.M. El-Khatib, L.A.E. Nassr, A.M. Abu-Dief, M. Ismael, A.A. Seleem, Spectrochim. Acta. 117, 366 (2014)

27. L.H. Abdel-Rahman, A.M. Abu-Dief, M.O. Aboelez, A.A.H. Abdel-Mawgoud, J. Photochem. Photobiol. B. 170, 271 (2017)

28. H. Laila. M.S. Abdel-Rahman, A.M. Adam, H. Abu-Dief, M. Moustafa, H. Basha, Ahmed, Aboria, Badriah Saad Al-Farhan, H. El-Sayed Ahmed. Appl Organometal Chem 32, e4527 (2018)

29. M. Ahmed. H.M. Abu-Dief, M.R. El-Sagher, Shehata, Appl Organometal Chem. 33, e4943 (2019)

30. L.H. Abdel-Rahman, A.M. Abu-Dief, H. Moustafa, A.A.H. Abdel-Mawgoud, Arabian J. of Chem. 13(1), 649-670 (2020)

31. H.R. Mardani, H. Golchoubian, J. Mol. Catal. A: Chem. 259, 197-200 (2006)

32. J.A.L. da Silva, J.J.R. Frausto da Silva, A.J.L. Pombeiro, Coord. Chem. Rev. 255, 2232-2248 (2011)

\section{Figures}




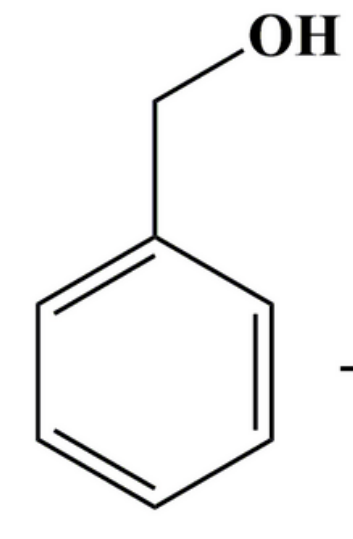

benzyl alcohol

\section{catalyst $+\mathrm{H}_{2} \mathrm{O}_{2}$} acetonitrile

Figure 1

Oxidation reaction of benzyl alcohol.
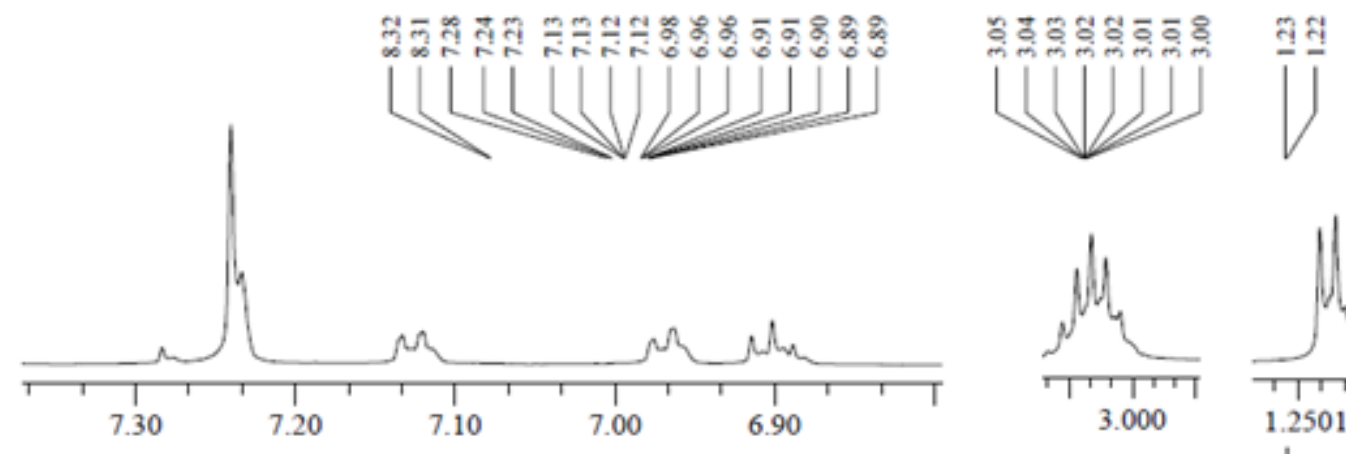

benzaldehyde

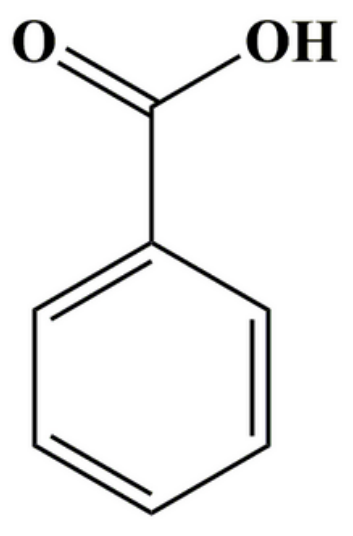

benzoic acid
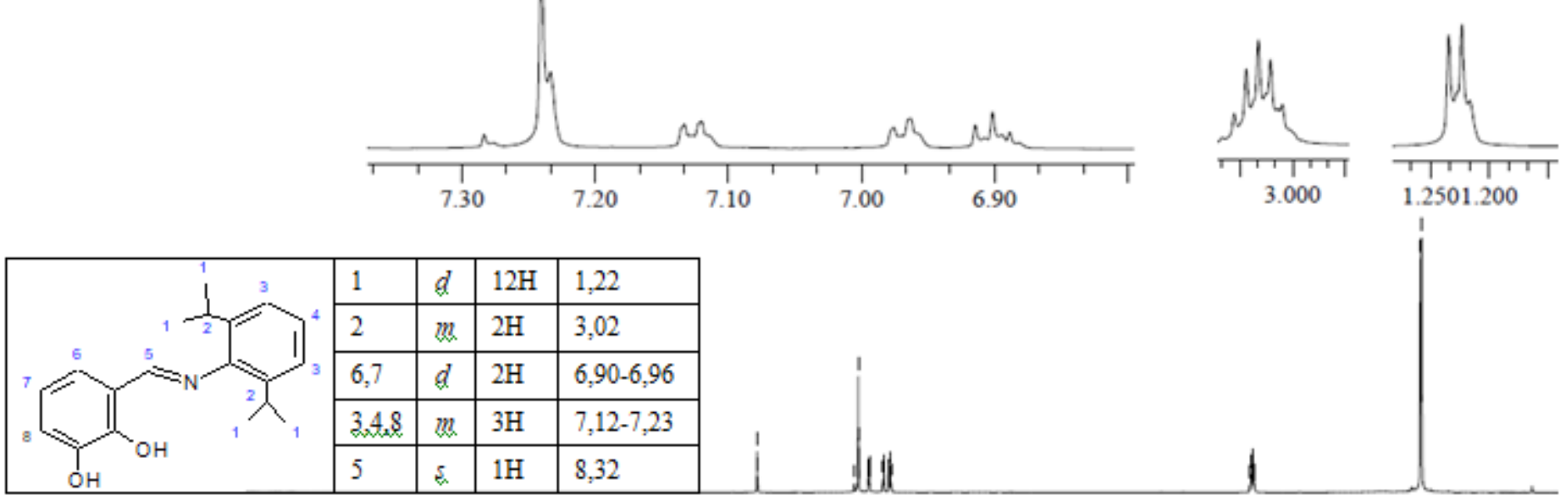

\begin{tabular}{|l|l|l|l|}
\hline 1 & $d$ & $12 \mathrm{H}$ & 1,22 \\
\hline 2 & $m$ & $2 \mathrm{H}$ & 3,02 \\
\hline 6,7 & $d$ & $2 \mathrm{H}$ & $6,90-6,96$ \\
\hline $3,4,8$ & $m$ & $3 \mathrm{H}$ & $7,12-7,23$ \\
\hline 5 & $s$ & $1 \mathrm{H}$ & 8,32 \\
\hline
\end{tabular}
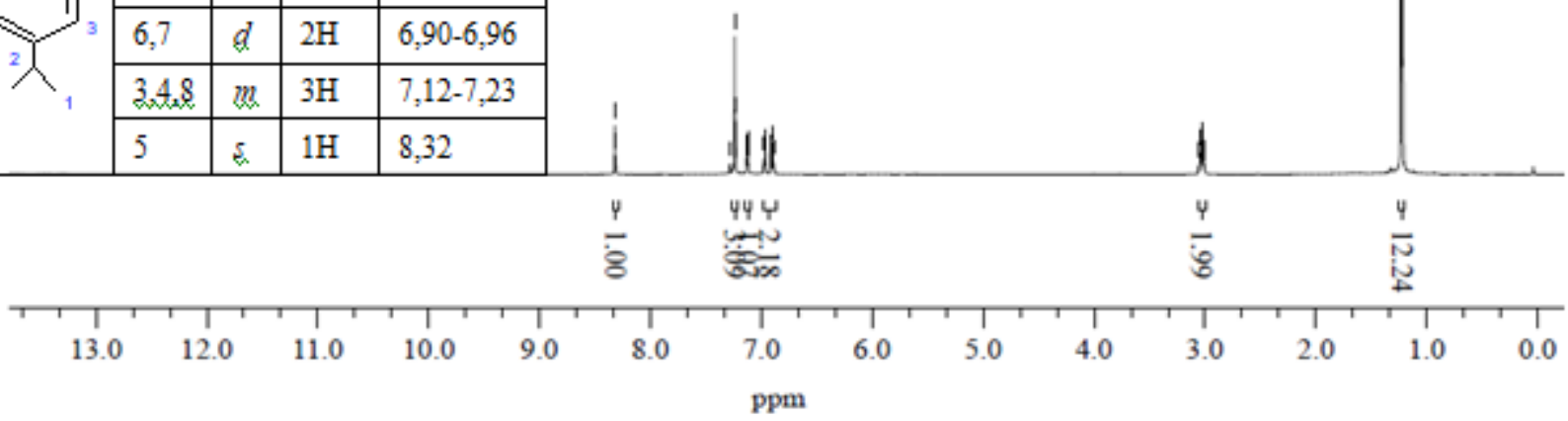

Figure 2

1H-NMR spectrum of HL1 ligand. 

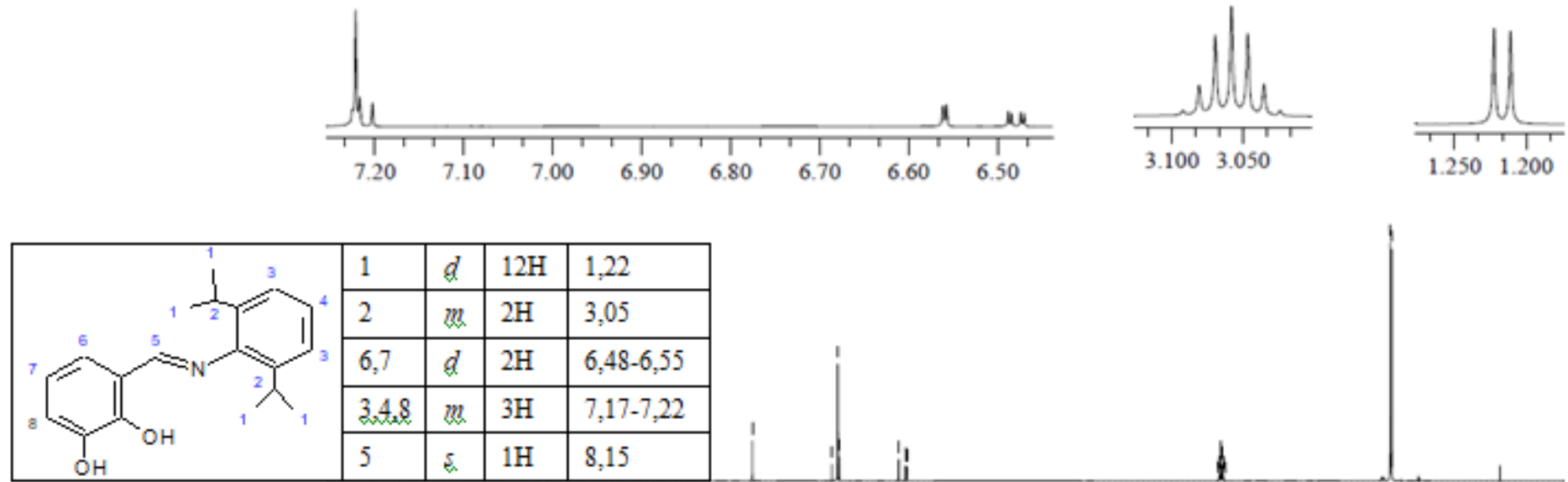

\begin{tabular}{|l|l|l|l|}
\hline 1 & $d$ & $12 \mathrm{H}$ & 1,22 \\
\hline 2 & $m$ & $2 \mathrm{H}$ & 3,05 \\
\hline 6,7 & $d$ & $2 \mathrm{H}$ & $6,48-6,55$ \\
\hline $3,4.8$ & $m$ & $3 \mathrm{H}$ & $7,17-7,22$ \\
\hline 5 & $s$ & $1 \mathrm{H}$ & 8,15 \\
\hline
\end{tabular}

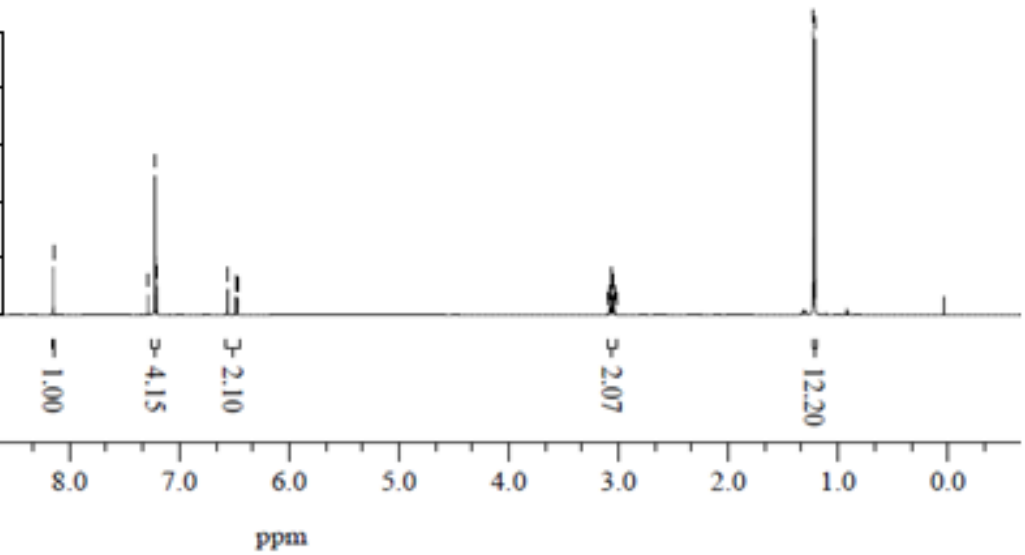

Figure 3

1H-NMR spectrum of HL2 ligand.

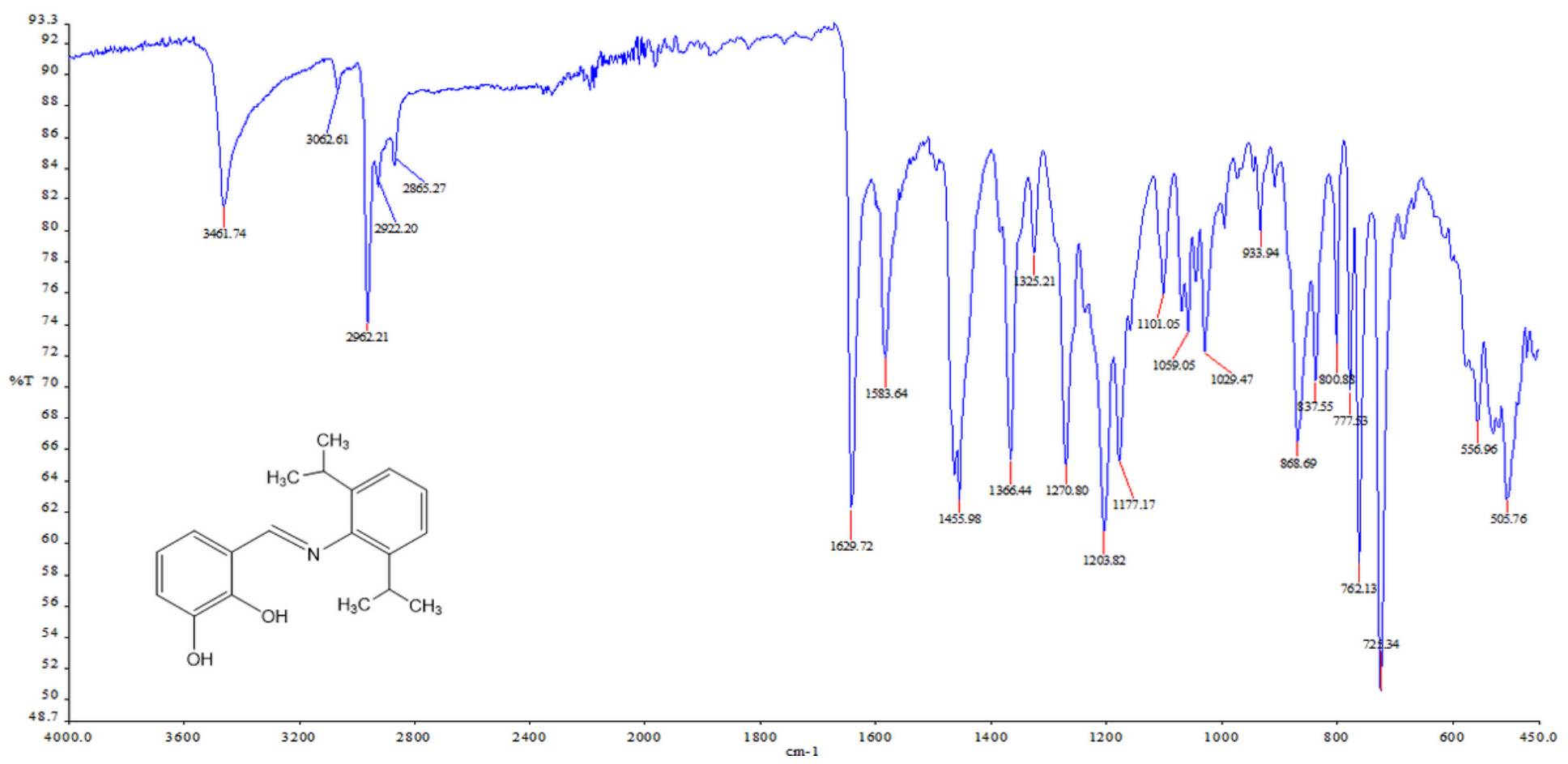

Figure 4

FT-IR spectrum of HL1 ligand. 


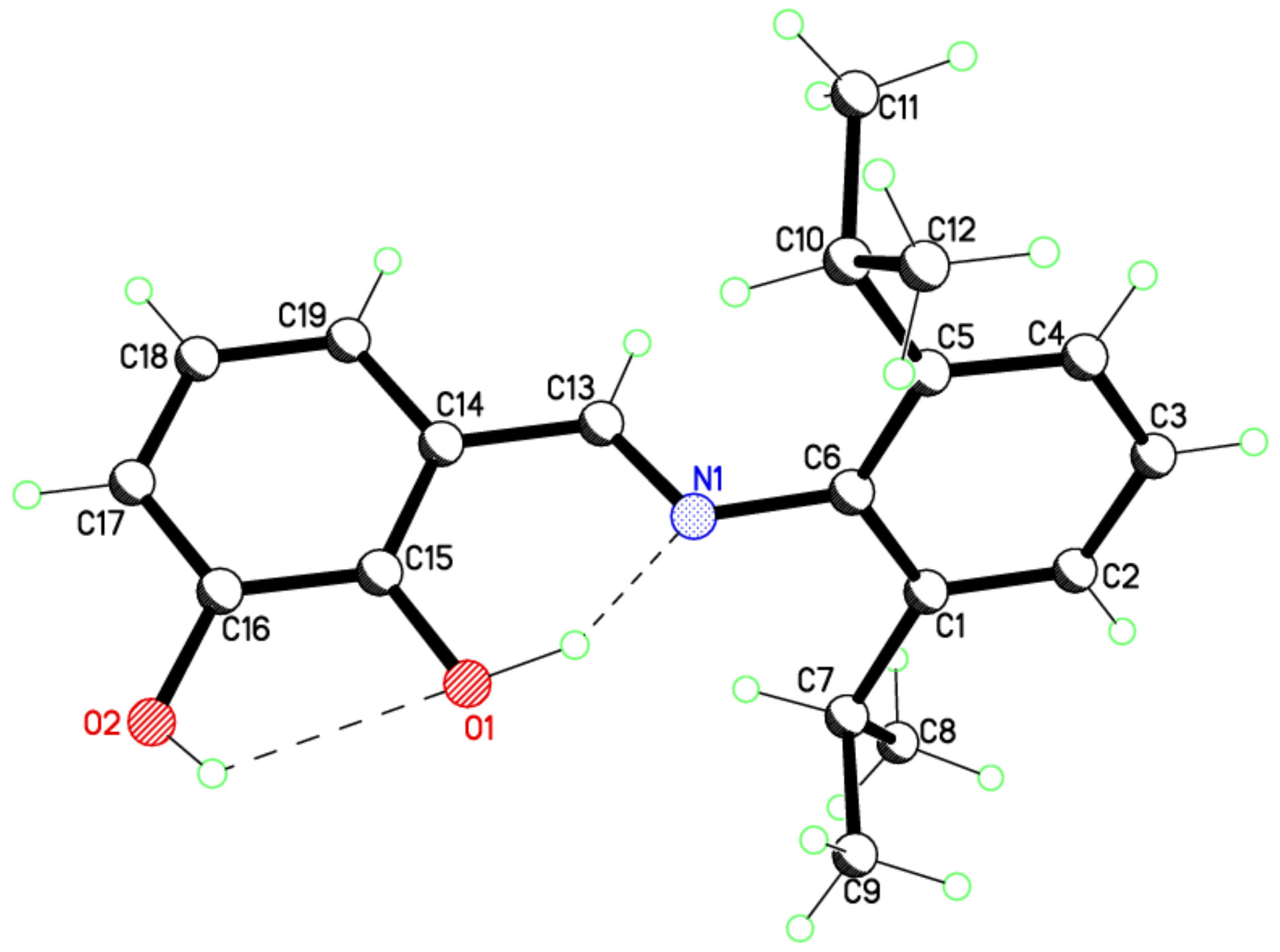

Figure 5

Molecular structure of HL1. Hydrogen bonds are shown as dashed lines. 


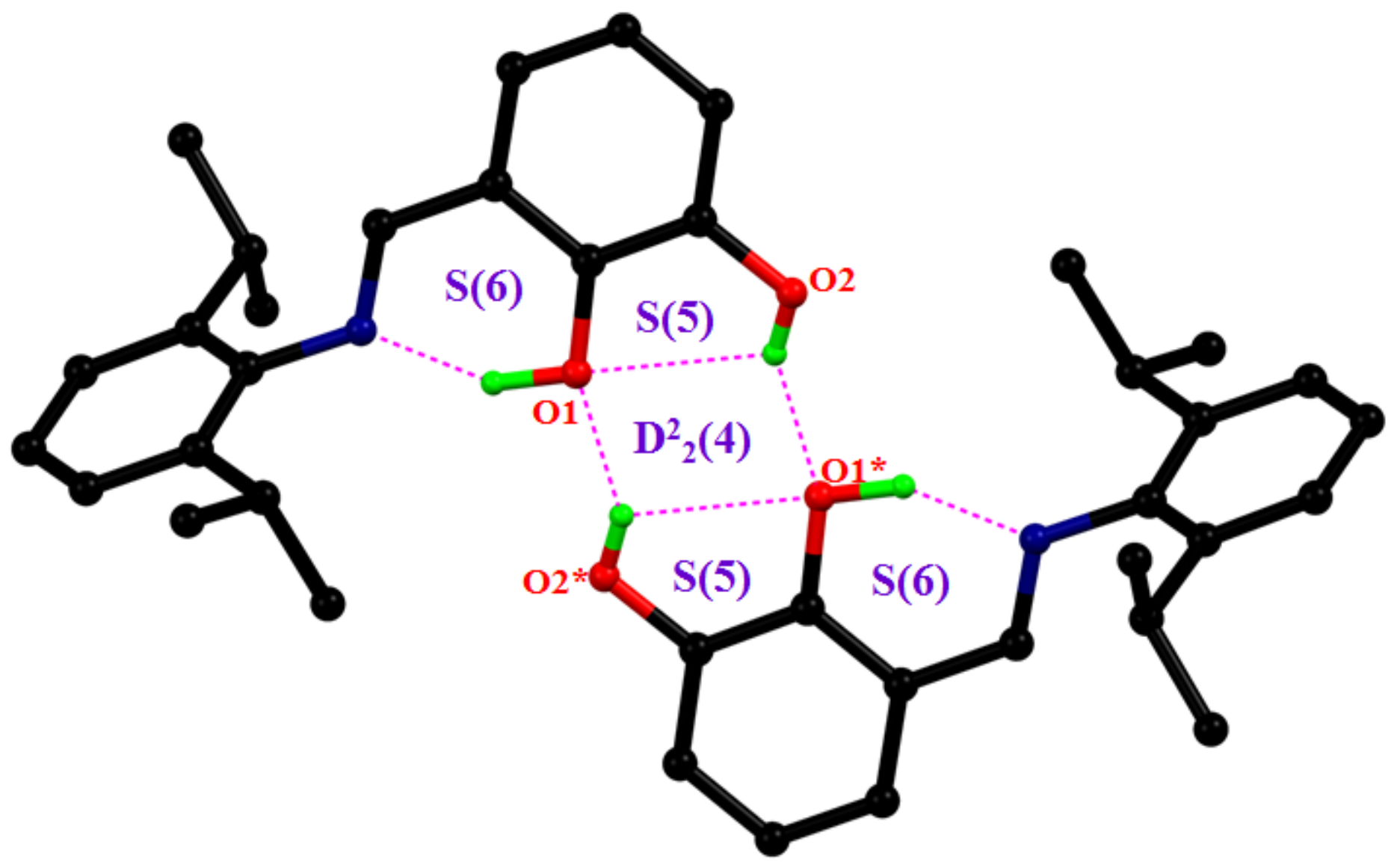

Figure 6

Hydrogen bond dimer in HL1. Hydrogen atoms bonded to carbon atoms are omitted for clarity (symmetry code*: $-x, 0.5+y, 0.5-z)$.

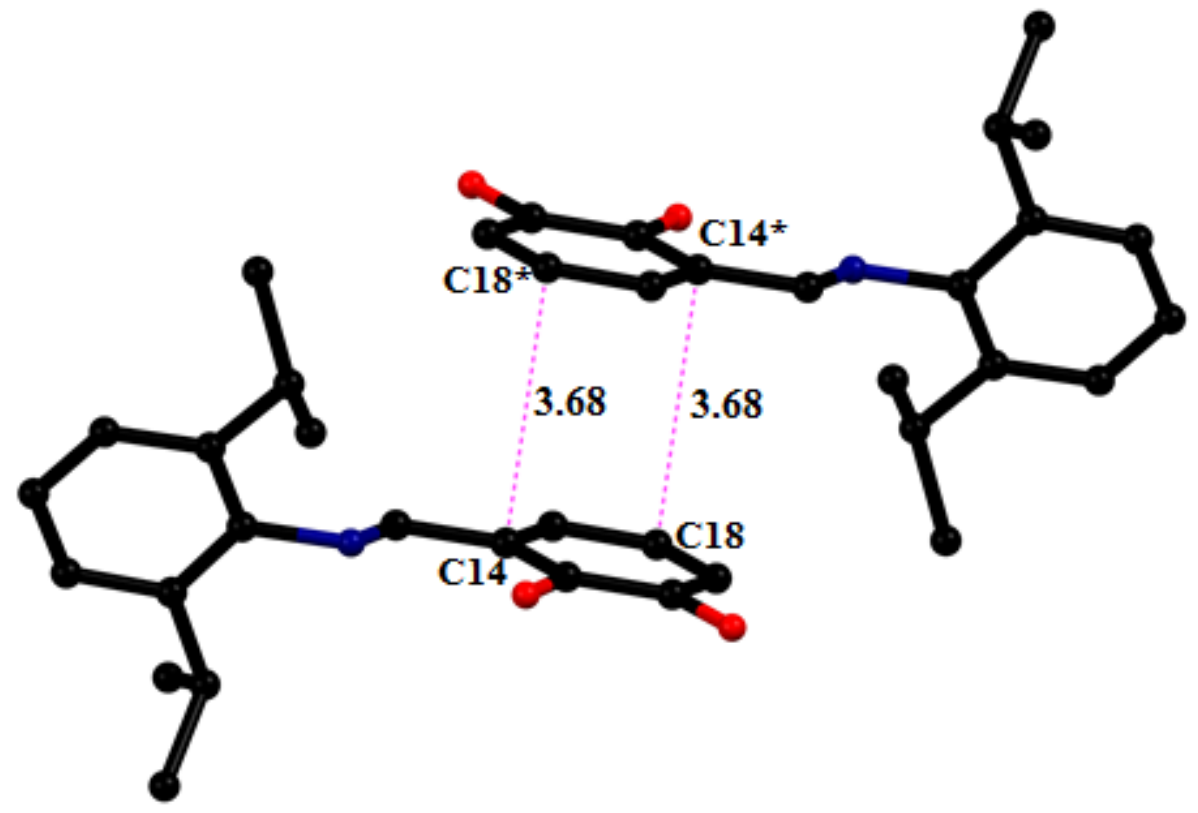

Figure 7

The $\pi-\pi$ stacking interactions in HL1 (symmetry code*: - $-\mathrm{x},-\mathrm{y}, 1-\mathrm{z})$. 


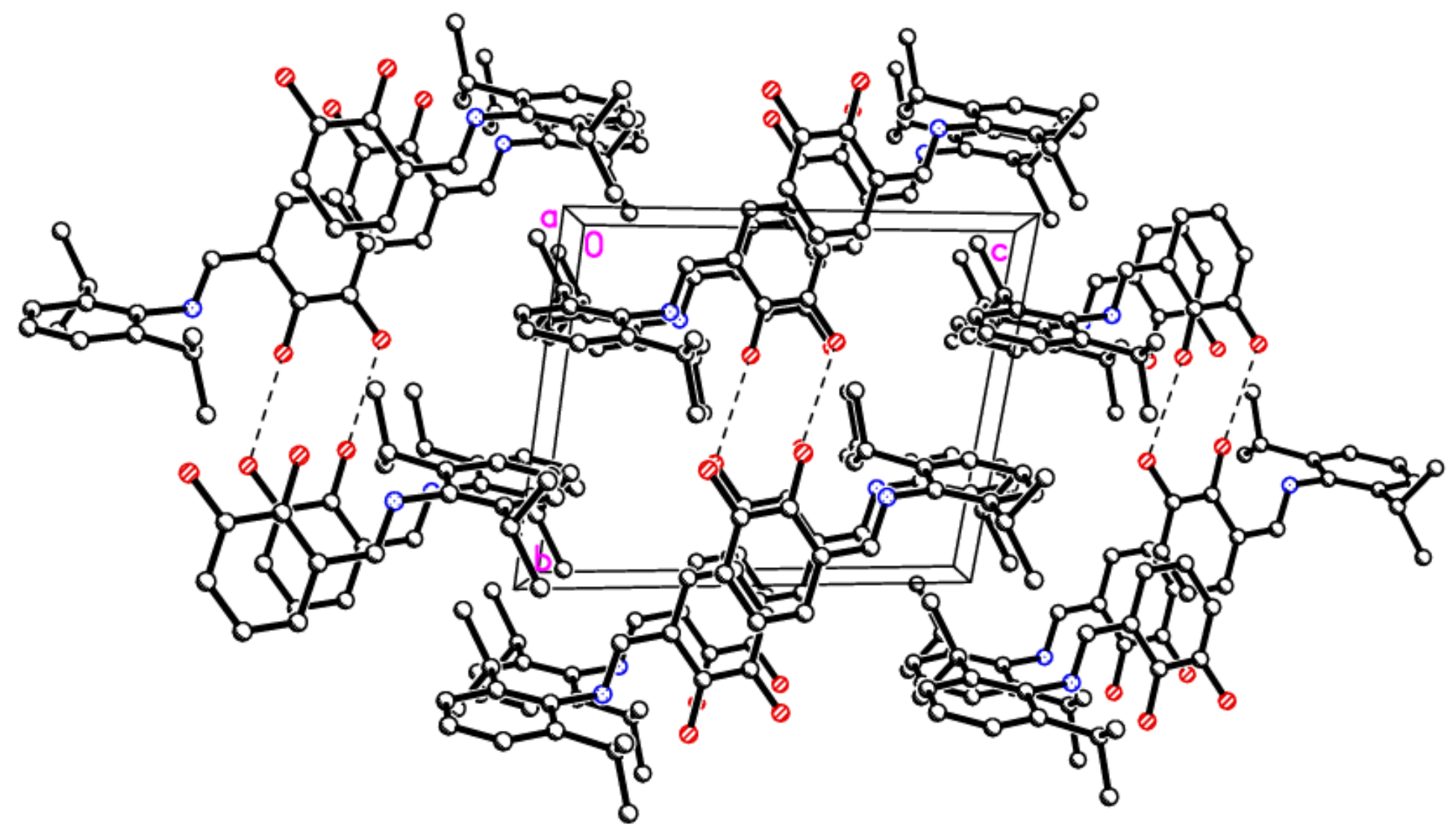

Figure 8

The packing diagram of HL1 viewing down the a axis. 


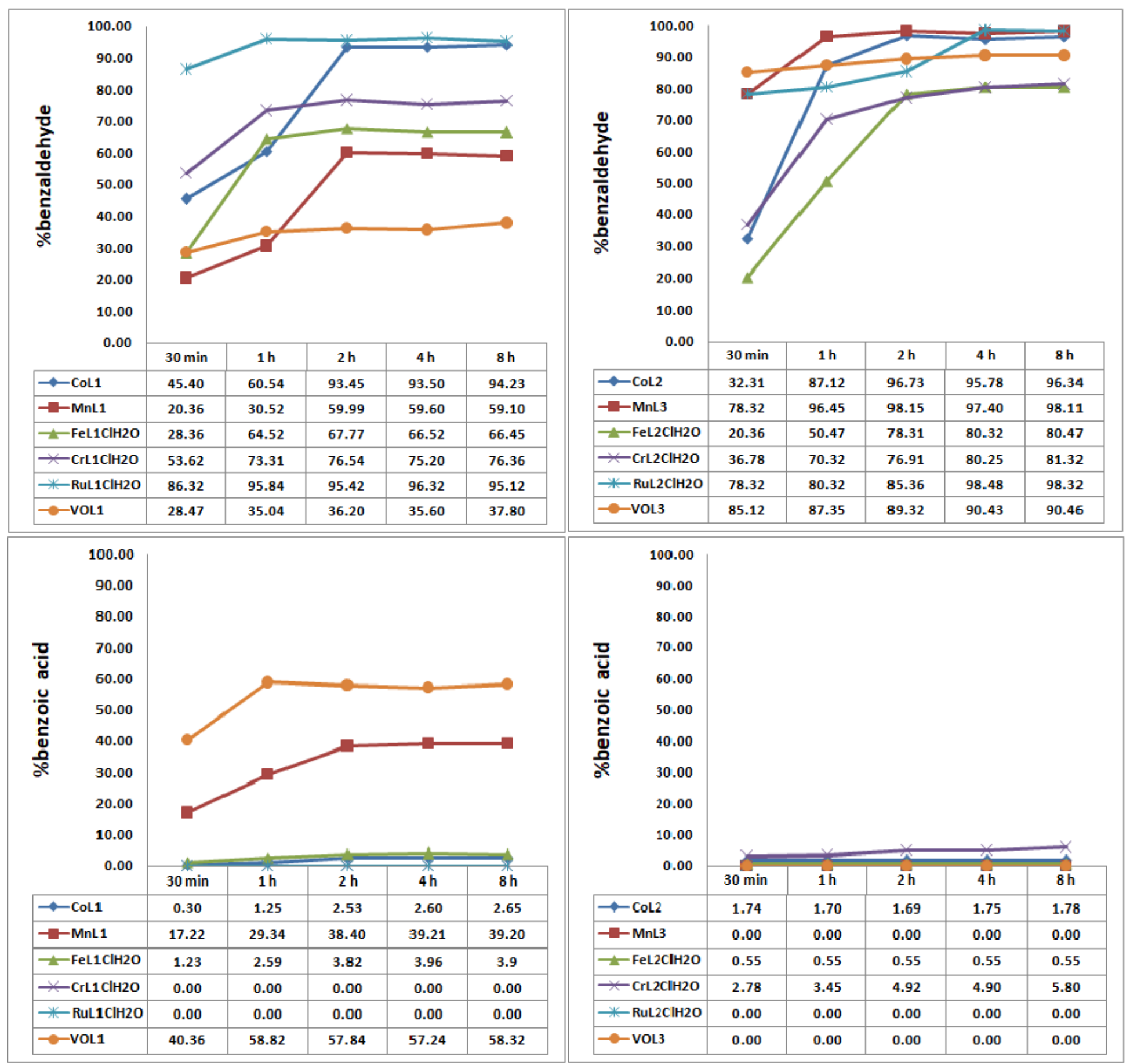

\section{Figure 9}

Time-dependent catalyst effects of metal complexes in benzyl alcohol oxidation. 


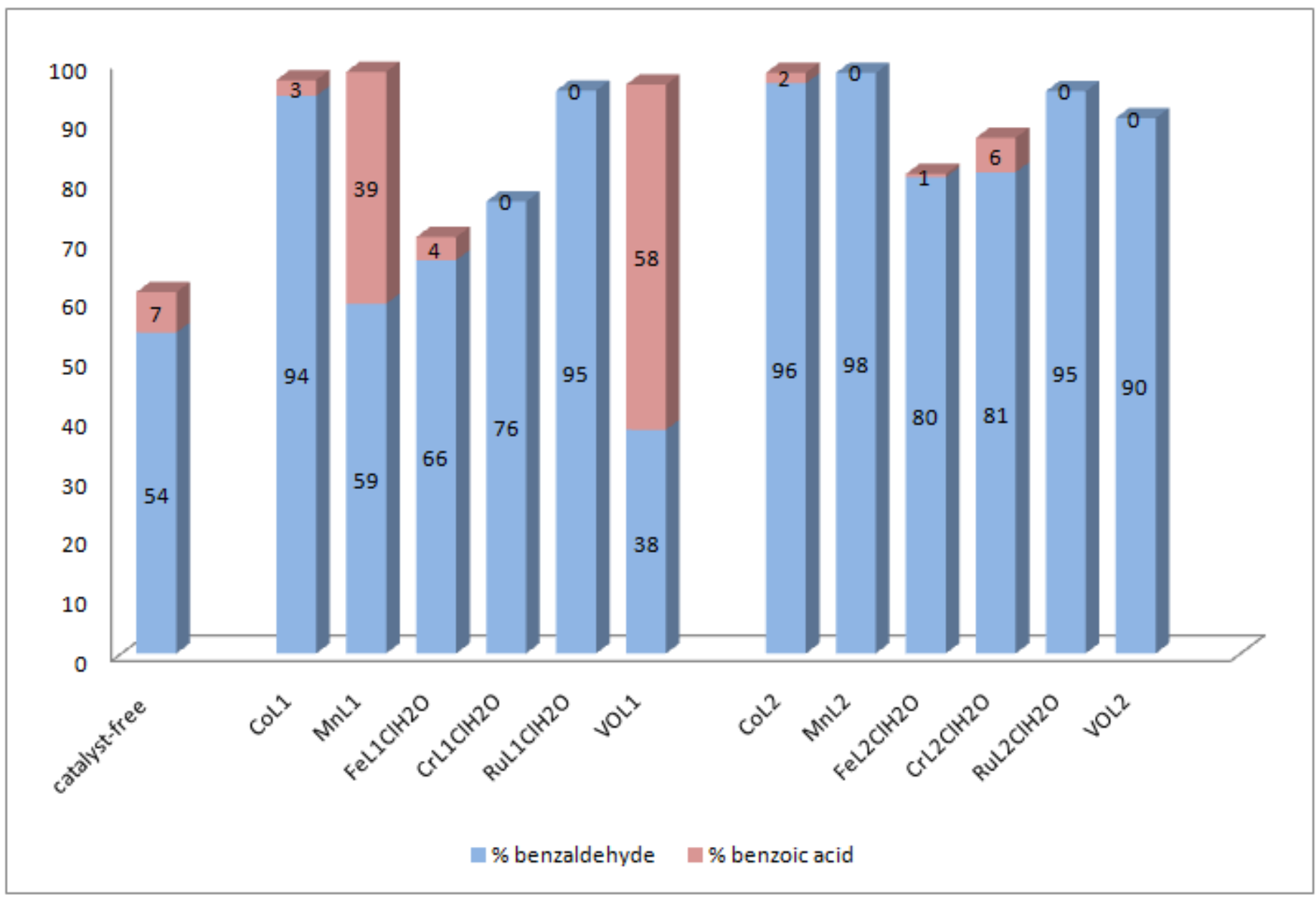

Figure 10

Catalyst effects of metal complexes in benzyl alcohol oxidation ( $8 \mathrm{~h})$.

\section{Supplementary Files}

This is a list of supplementary files associated with this preprint. Click to download.

- Scheme01.png

- Scheme02.png

- Supplementray.doc 